\title{
Sentinel-2 imageries with meteorological data utilize remote sensing and GIS for wheat crop prove production
}

\author{
Muslim Sbahi ${ }^{1, *}$, Abdul-Razzak Ziboon ${ }^{1}$ and Khalid Hassoon ${ }^{2}$ \\ ${ }^{1}$ Building and Construction Engineering Department, University of Technology, Baghdad, Iraq \\ ${ }^{2}$ Ministry of Science and Technology, Baghdad, Iraq
}

\begin{abstract}
Agricultural statistics are considered one of the most important topics in the developed countries now. In addition to the irrigation systems used, they relate to the quality and quantity of production and the consequent export and import of agricultural crops in order to achieve food security for the country. Therefore, the present traditional methods used in the collection of statistical data are not sufficient to cover the vast areas of cultivated strategic crops and to determine the effects therein. This is due to many factors, the most important of which is climatic changes. Hence the importance of the application of remote sensing techniques for image and data in the survey, agricultural statistics and monitoring of the quality and quantity of production using the latest satellite images available free from the owner of artificial satellite Sentinel2 which has spatial resolution of $10 \mathrm{~m}$ instead of $30 \mathrm{~m}$ available in artificial satellite Landsat 8 . Research results showed that the temperature can be controlled using modern techniques used in irrigation, which improves the atmosphere and thus contribute to providing a suitable environment for the wheat crop, which helps to increase the amount of production these have been clearly monitored using applicable indicators derived from satellite imageries data.
\end{abstract}

\section{Introduction}

Remote Sensing (RS) as defined in many scientific sources, is the science and art of obtaining data about an object, area or phenomenon under monitoring. Through specialized software, data obtained without physical contact is analyzed and information is generated about these phenomena [1]. At present, remote sensing techniques in most developed countries have become one of the most important methods used to monitor terrestrial environmental changes, particularly agricultural areas. The importance of monitoring the agricultural areas is due to the vast areas cultivated and the difficulty to control by traditional methods (field visits) and determine the areas and health status of the crops and their need for nutrition. In addition, agricultural production is linked to food security. Using technology, processing and analysis of remote sensing data and modern computers assist surveyors in measuring and monitoring the Earth's natural resources and identify changes periodically [2]. The Sentinel-2 satellite was launched on 23 June 2015 and received the first data within a selected study area on December 19, 2015. It continued to send data until the end of the monitoring process on 8 March 2016 by five satellite imageries. The Sentinel-2 is characterized by spatial resolution of 10 meters, which is suitable in determining the areas and health status of areas estimated at hundreds of donum suitable according to the criteria of remote sensing [3]. The meteorological data obtained from the Iraqi Ministry of Agriculture stations were linked to theoretical results of the imageries analysis in order to enhance the results because of significant impact on the crops. Research works to employ modern techniques of meteorological stations daily and Satellite Sentinel-2 imageries with high spatial resolution improve the the production of the wheat crop.

\section{Objectives}

The research aims to use modern techniques represented by using imageries of satellite Sentinel-2 that has made use of its data for the first time. In addition, integration of the satellite data and daily agricultural meteorologist and atmospheric data network affiliated to the Iraqi Ministry of Agriculture can predict the annual crop of wheat and derive the amount of output for large areas with high accuracy and less cost and effort.

\section{Study areas}

Areas of research and study are located in the Middle Euphrates region of Iraq in the province of Karbala; the first area is east of the province within the borders of AlHassainya Nahia and is called Agriculture Division of Imam Aoun. The second study area is west of the province within the borders of Ain al-Tamur Nahia and is called Agriculture Division of Ain al-Tamur (Fig. 1).

* Corresponding author: surveyor.moslem@gmail.com 
Agriculture Division of Imam Aoun depends on surface irrigation using electric pumps and the nature of the distribution of farms is irregular in forms and the soil is not fertile. The Agriculture Division of Ain al-Tamur has fertile soil and is characterized by farms with circle shape depending on the nature of the fixed pivot spraying irrigation, which depends on water artesian wells.

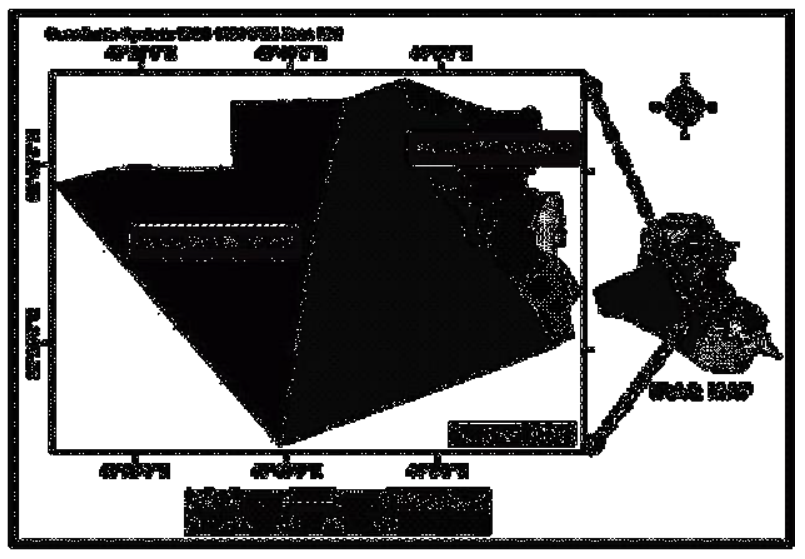

Fig. 1. Iraq map with location study areas in the holy province of Karbala

\section{Theoretical background}

\subsection{Growth stage scales}

The chart or table of crop growth stages is very important in order to describe the growth stages of each crop. It is important to understand the growth and development of wheat from sowing to maturity and harvesting for the proper use of fertilizers and pesticides to ensure the safety of the crop [4]. Many of the determinants and signs of increases constrain in use until certain stages of growth have been achieved. A widely used scale in the United States is the scale Feekes [5]. Feekes is distinguished from other measures as it gives a general description of the stages of the wheat crop growth which helps monitor the growth process by using remote sensing techniques to understand the changes taking place.

\subsection{Growth stage scales}

Agricultural meteorological stations of modern techniques are used in the collection of meteorological data. The stations are located in the center of the areas of study (see Fig. 2) for data to be collected in an orderly manner and accurate monitoring. Monitoring is done of several air elements which affect agricultural production. The meteorological stations monitor both degree of minimum and maximum temperature, the intensity of solar radiation as well as relative humidity of minimum and maximum, in addition to the many other elements. Temperature is one of the most important factors affecting the determination of the amount of agricultural production, as well as the production of agricultural crops through their direct and indirect effects.
Temperature affects the growth stages of different physiological processes occurring within the crop, as well as determines the places of spread and concentration of the crop in different geographic regions [6]. Thus, three temperature ranges (minimum, optimal, and maximum) for wheat crop were identified as shown in Table 1.

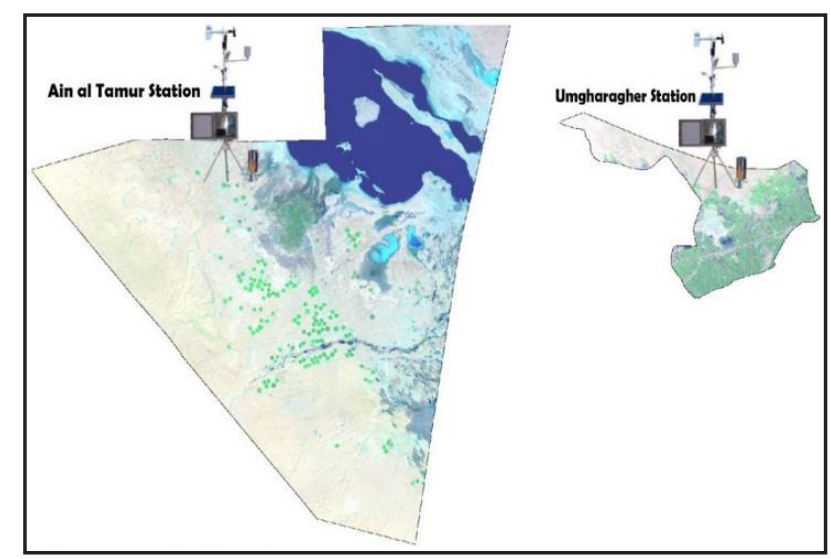

Fig. 2. The meteorological stations location for Imam Aoun and Ain al Tamur in the Holy Karbala' province

Table 1. Températures limites of the wheat crop

\begin{tabular}{|c|c|c|c|c|}
\hline $\begin{array}{l}\text { Wheat } \\
\text { Growth } \\
\text { Stages }\end{array}$ & Month & $\begin{array}{c}\text { Maximu } \\
\text { m Temp. } \\
C^{\circ}\end{array}$ & $\begin{array}{l}\text { Optimum } \\
\text { Temp. } C^{\circ}\end{array}$ & $\begin{array}{l}\text { Minimum } \\
\text { Temp. C }\end{array}$ \\
\hline $\begin{array}{c}\text { Planting } \\
- \\
\text { Emerge } \\
\text { nce }\end{array}$ & $\begin{array}{c}\text { Novemb } \\
\text { er }\end{array}$ & 30 & 18 & 12 \\
\hline $\begin{array}{c}\text { Emerge } \\
\text { nce- } \\
\text { Start } \\
\text { Tillering }\end{array}$ & $\begin{array}{c}\text { Decemb } \\
\text { er }\end{array}$ & 20 & 13 & 3 \\
\hline $\begin{array}{l}\text { Vegetati } \\
\text { ve } \\
\text { Tillering } \\
\text { Growth }\end{array}$ & $\begin{array}{c}\text { January } \\
- \\
\text { Februar } \\
\text { y }\end{array}$ & 22 & 17 & 10 \\
\hline Heading & March & 30 & 22 & 15 \\
\hline $\begin{array}{c}\text { Ripenin } \\
\mathrm{g}\end{array}$ & $\begin{array}{l}\text { April - } \\
\text { May }\end{array}$ & 40 & 25 & 17 \\
\hline
\end{tabular}

\subsection{Growth stage scales}

The Normalized Difference Vegetation Index (NDVI) law see equation (1), is used to calculate the vegetative intensity related to the health status of crops affected by external and internal surroundings of the crop. Moreover, data from remote sensing can be considered 
the best and fastest method as compared to the conventional way to efficiently manage nitrogen [7]. The equation (2) is used for change detection the contrast between two images for same band. The equation (3) is used for change detection the NDVI between two images at difference date. The logic of image algebra is for change detection using image differencing or band rationing [9].

$$
N D V I=(\operatorname{Red}-N I R) /(\operatorname{Red}+N I R)
$$

Where:

NIR $=($ Near-Infrared band $)$

Red $=($ band visible $)$

$$
\triangle B V a, b, d=B V a, b, d(1)-B V a, b, d(2)+c
$$

Where:

$\triangle \mathrm{BV}$ a $, \mathrm{b}, \mathrm{d}=$ change in pixel value

$\mathrm{BV}$ a, $\mathrm{b}, \mathrm{d}(1)=$ brightness value on date one

$\mathrm{BV} a, b, \mathrm{~d}(2)=$ brightness value on date two

$\mathrm{c}=\mathrm{a}$ constant (e.g. 127)

$\mathrm{a}=$ line No

$\mathrm{b}=$ column No.

$\mathrm{d}=\mathrm{a}$ single band (e.g. Sentinel-2 band 13)

$$
\triangle N D V I a, b=N D V I a, b(1)-N D V I a, b(2)+c
$$

Where:

$\triangle$ NDVI $a, b=$ change pixel value at NDVI

NDVI $a, b(1)=$ NDVI value on date one

NDVI $a, b(2)=$ NDVI value on date two

\section{Methodology}

\subsection{Work steps}

Research depended on the following data (Fig. 3):

1. Calculation of crop germination calendar using CROPWAT 8.0 is a tool to support decision-making by the land and water development division of Food and Agriculture Organization (FAO).

2. Sentinel-2 Satellite Data Starting download from 19 December 2015 to 08 March 2016 with five image.

3. Meteorological Data that it has been received from the Meteorological stations affiliated to the Iraqi Ministry of Agriculture. It included data (degree of temperature minimum and maximum, relative humidity minimum and maximum, intensity of solar radiation, wind speed and direction)

4. Field Survey Data include crop growth data, coordinates crop positions, and verification of field sampling data.

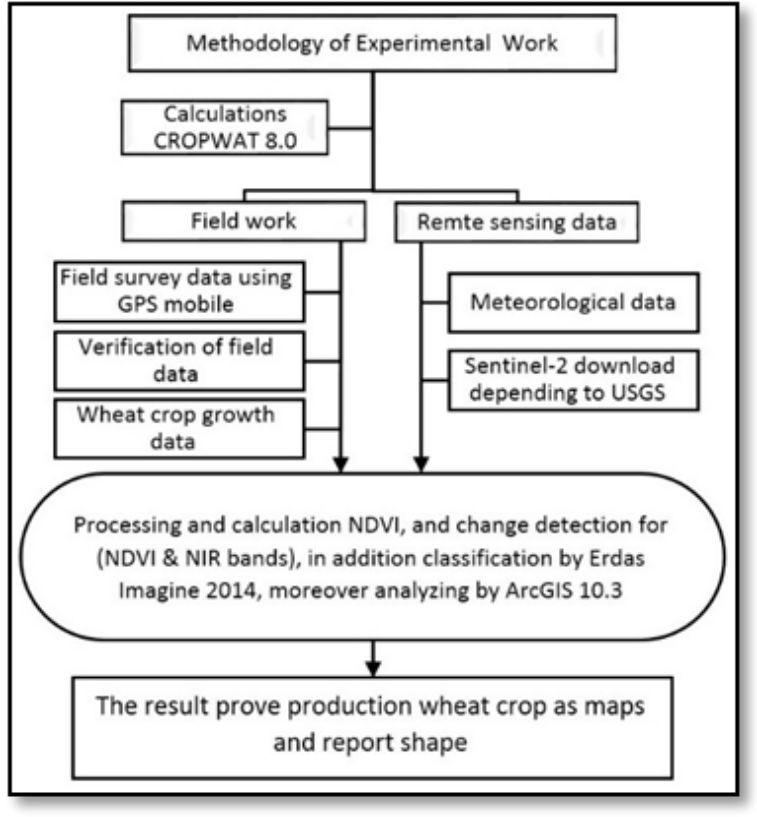

Fig. 3. Steps research methodology with study materials

\subsubsection{Data collection and analysis stage for Agriculture Division of Imam Aoun.}

Farm data (C \& E) that depend on surface irrigation, which take irregular forms as in Fig. (4 \& 7). Using ERDAS IMAGINE program has been for spectral reflectance calculation of the five samples installed on each farm see Fig. ( $5 \& 8)$ with the coordinates of taken samples as in the Table ( $2 \& 3)$. Field visits each month for final samples described as representing the production of the final average farm see Fig. (6\&9).

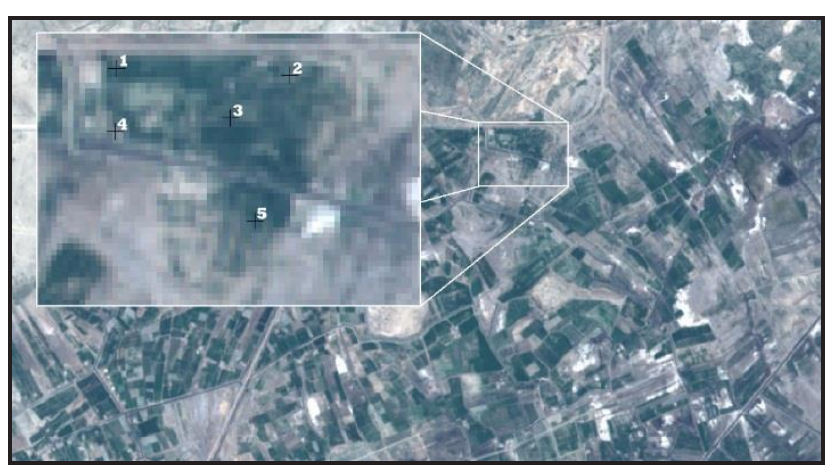

Fig. 4. Sentinel-2 image scene on 8-march 2017 shown Farm $\mathrm{C}$ with the five samples.

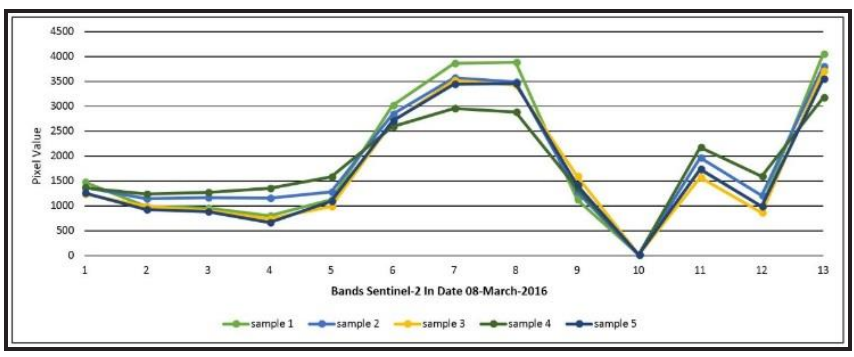

Fig. 5. Spectral profile for the five samples at the Farm $\mathbf{C}$ 
Table 2. The coordinates of the samples the farm $\mathbf{C}$

\begin{tabular}{|c|c|c|}
\hline No. sample & $\mathbf{E}$ & $\mathbf{N}$ \\
\hline 1 & 423592.998601 & 3625900.39598 \\
\hline 2 & 423905.721972 & 3625887.10349 \\
\hline 3 & 423798.682429 & 3625810.84656 \\
\hline 4 & 423590.899787 & 3625787.7596 \\
\hline 5 & 423842.05793 & 3625625.45127 \\
\hline \multicolumn{2}{|c|}{ Coordinates system : WGS 1984 UTM Zone 38N } \\
\hline
\end{tabular}

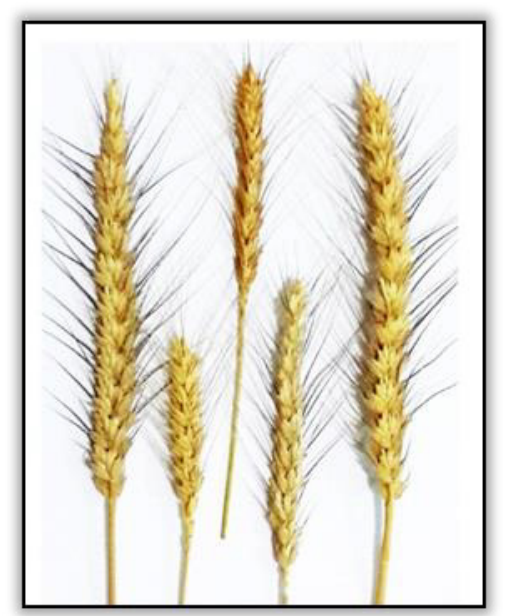

Fig. 6. The final production of the Farm $\mathbf{C}$

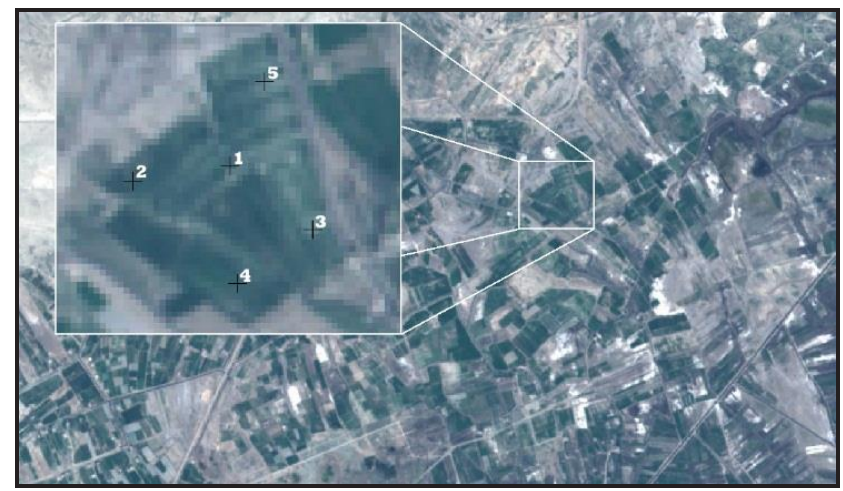

Fig. 7. Sentinel-2 image scene on 8-march 2017 shown Farm $\mathbf{E}$ with the five samples.

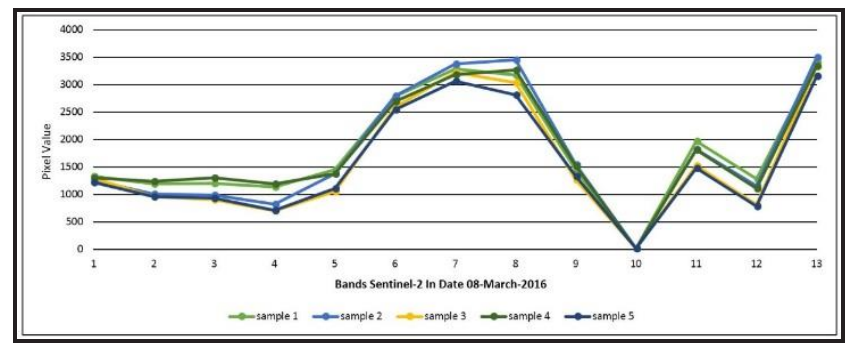

Fig. 8. Spectral profile for the five samples at the Farm $\mathbf{E}$
Table 3. The coordinates of the samples the farm $\mathbf{E}$

\begin{tabular}{|c|c|c|}
\hline No. sample & $\mathbf{E}$ & $\mathbf{N}$ \\
\hline 1 & 424225.612287 & 3625358.47756 \\
\hline 2 & 424061.138242 & 3625334.08787 \\
\hline 3 & 424364.445891 & 3625251.53816 \\
\hline 4 & 424238.119819 & 3625160.85856 \\
\hline 5 & 424282.812659 & 3625501.64803 \\
\hline \multicolumn{2}{|c|}{ Coordinates system : WGS 1984 UTM Zone 38N } \\
\hline
\end{tabular}

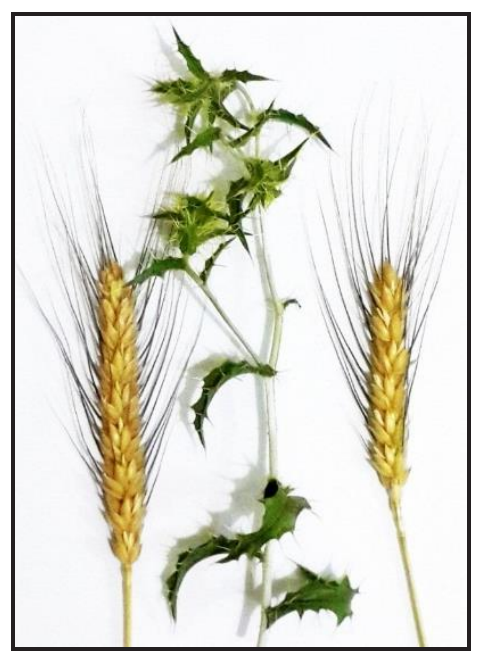

Fig. 9. The final production of the Farm $\mathbf{E}$

\subsubsection{Data collection and analysis stage for Agriculture Division of Ain al-Tamur.}

Farm data $(F \& G)$ that rely on fixed pivot irrigation (sprinkler) and the farms take circular forms of regular sizes $(60,80,120$ donum) depending on the length of the sprayer as in Fig. (10 \& 13). Using ERDAS IMAGINE program has been for spectral reflectance calculation of the five samples installed on each farm see Fig. (11 \& 14) with the coordinates of taking samples as in the Table $(4 \& 5)$. Field visits each month final samples described as representing the production of the final average farm see Fig. (12\& 15).

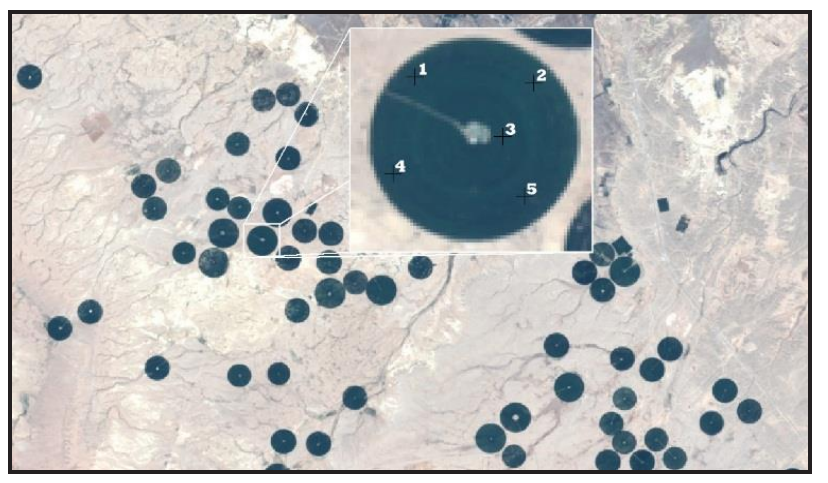

Fig. 10. Sentinel-2 image scene on 8-March 2017 showing Farm $\mathbf{F}$ with the five samples. 


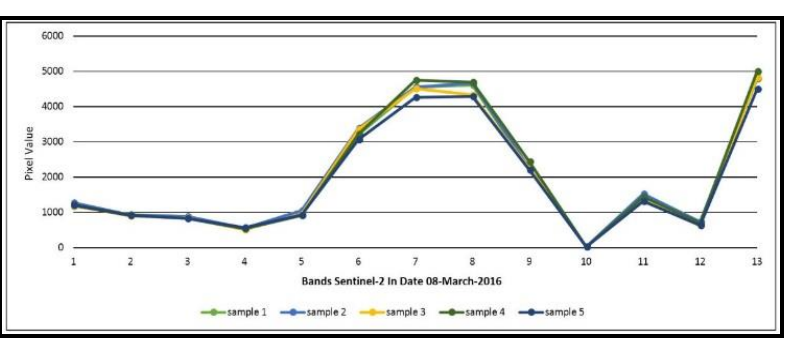

Fig. 11. Spectral profile for the five samples at the Farm $\mathbf{F}$

Table 4. The coordinates of the samples the farm $\mathbf{F}$

\begin{tabular}{|c|c|c|}
\hline No. sample & $\mathbf{E}$ & N \\
\hline 1 & 354750.993277 & 3598102.4246 \\
\hline 2 & 355107.519445 & 3598083.85552 \\
\hline 3 & 355013.436151 & 3597917.97182 \\
\hline 4 & 354685.382559 & 3597805.31946 \\
\hline 5 & 355079.046869 & 3597734.75698 \\
\hline \multicolumn{3}{|c|}{ Coordinates system : WGS 1984 UTM Zone 38N } \\
\hline
\end{tabular}

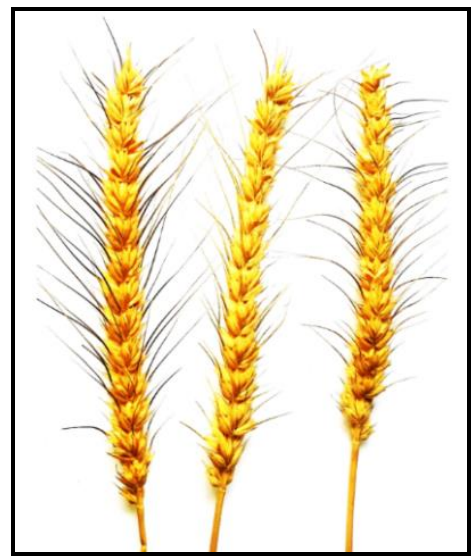

Fig. 12. The final production of the Farm $\mathbf{F}$

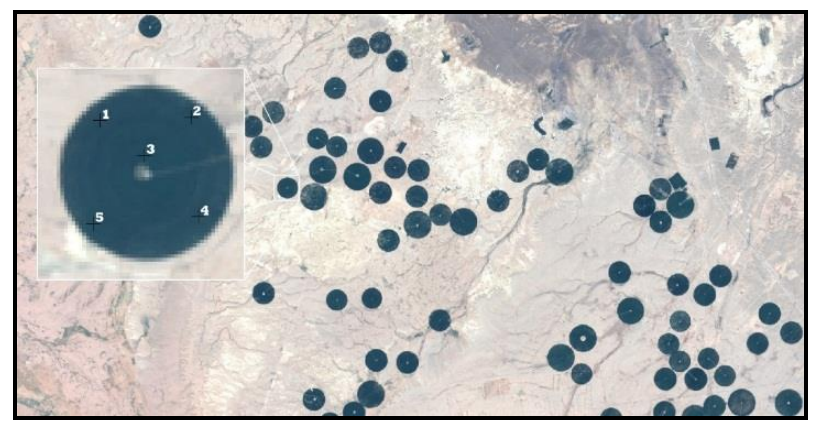

Fig. 13. Sentinel-2 image scene on 8-March 2017 showing Farm $\mathbf{G}$ with the five samples.

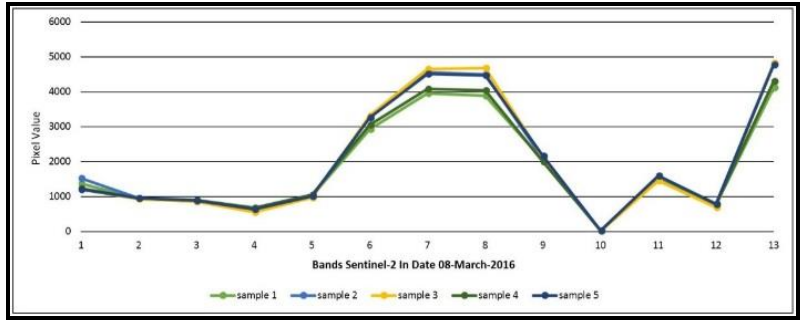

Fig. 14. Spectral profile for the five samples at the Farm $\mathbf{G}$

Table 5. The coordinates of the samples the farm $\mathbf{G}$

\begin{tabular}{|c|c|c|}
\hline No. sample & $\mathbf{E}$ & $\mathbf{~ N}$ \\
\hline 1 & 353222.651975 & 3597798.6622 \\
\hline 2 & 353471.010036 & 3597806.63091 \\
\hline 3 & 353344.17477 & 3597703.03771 \\
\hline 4 & 353491.595865 & 3597537.68702 \\
\hline 5 & 353205.386441 & 3597517.76525 \\
\hline \multicolumn{2}{|c|}{ Coordinates system : WGS 1984 UTM Zone 38N } \\
\hline
\end{tabular}

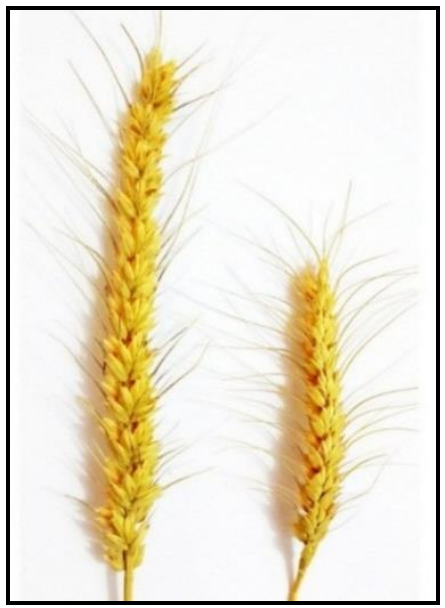

Fig. 15. The final production of the Farm $\mathbf{G}$

\subsubsection{Calculation NDVI and change detection (NDVI and NIR band) for Agriculture Divisions.}

The NDVI was calculated with change detection (NDVI $\&$ NIR band) for both Agriculture Divisions see Fig. (16 $\&$ 17). In addition, the Meteorological data linking theory with the results of indicators pointing to the reasons for the weakness and strength of signal indicators, which affect the quantity and quality of the final crop. 


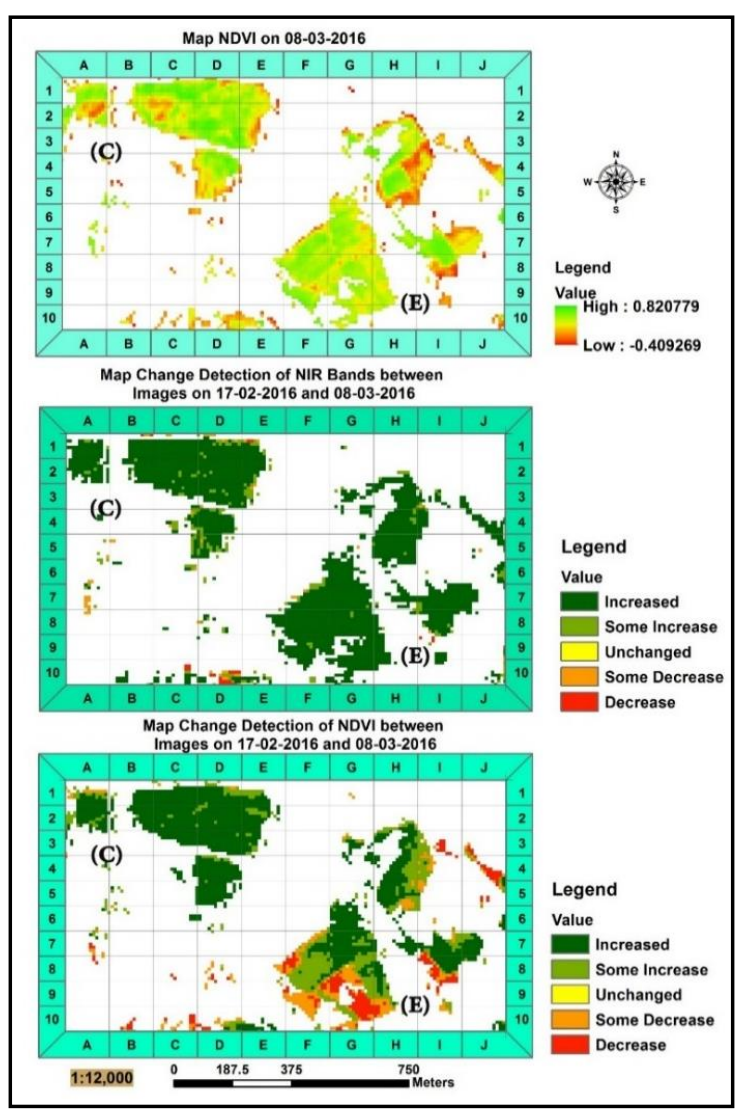

Fig. 16. Scenes NDVI on 8-March 2017 and change detection between NDVI \& NIR band on (17-02-2017 \& 08-03-2017) showing Farms C \& E at Agriculture Division of Imam Aoun.

Table 6. Supervised classification results of the Agriculture Division of Imam Aoun

\begin{tabular}{|c|c|c|}
\hline \multirow{2}{*}{ Data } & Difference & $\begin{array}{c}\text { Maximum } \\
\text { likelihood }\end{array}$ \\
\hline & $\begin{array}{c}\text { Overall } \\
\text { classification } \\
\text { accuracy }\end{array}$ & $94.32 \%$ \\
\cline { 2 - 3 } $\begin{array}{c}\text { Sentinel-2 image } \\
\text { on 08-03-2016 }\end{array}$ & $\begin{array}{c}\text { Overall statistics } \\
\text { kappa }\end{array}$ & $\mathbf{0 . 9 3 5 1}$ \\
\cline { 2 - 3 } & $\begin{array}{c}\text { Area of wheat } \\
\text { crop }\end{array}$ & $\mathbf{2 8 1 4 \text { Donum }}$ \\
\hline
\end{tabular}

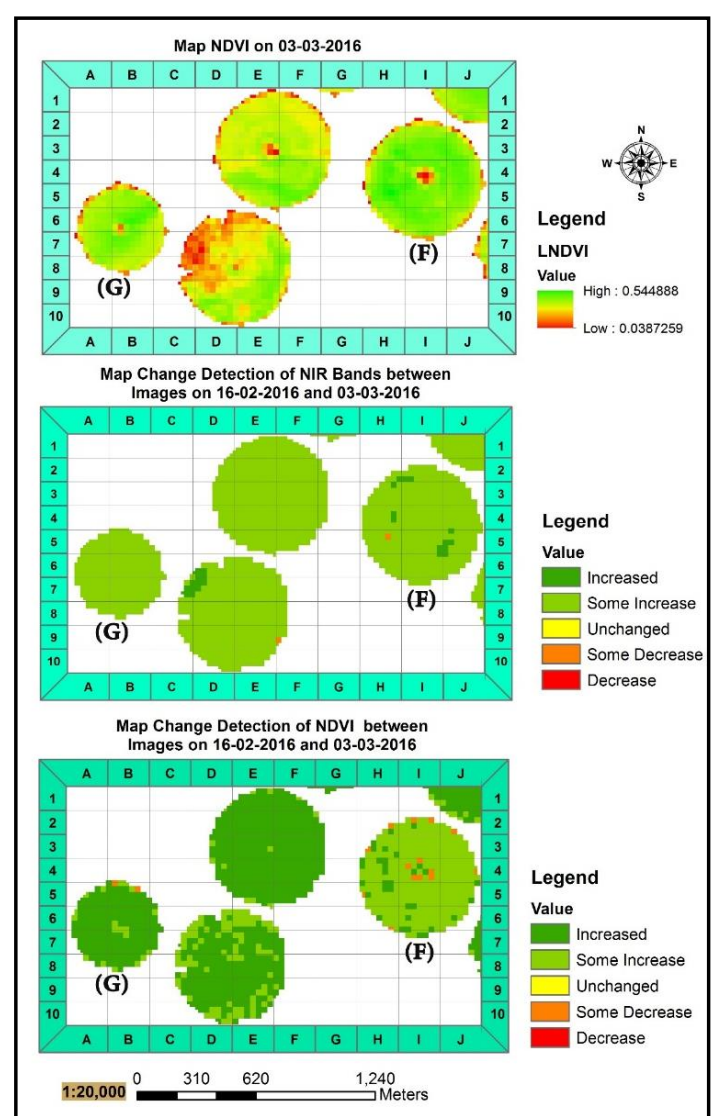

Fig. 17. Scenes NDVI on 8-March 2017 and change detection between NIR band \& NDVI on (17-02-2017 \& 08-03-2017) showing Farms G \& F.

\subsubsection{Classification stage to Agriculture Divisions.}

Classification of both the regions of the study has been using the method of Maximum likelihood. Classification accuracy showed good results as in the Table $(6 \& 7)$. The quantity of wheat crop decreased by 686 donum from proven in the agricultural plan at Agriculture Division of Imam Aoun. While the Ain al-Tamur Agriculture Division has seen a marked rise in the quantity of production up to 3200 donum from what was mentioned in Sticky agricultural plan. See Fig. (18 \&19). The first study area was classified into eight categories depending on the field visits and the points that were monitored using GPS, which proved the existence of different types of soil, random residential areas, palm trees, wheat and barley crops, as well as some water sources. While the second study, area was classified into five categories because of the lack of ground phenomena. 


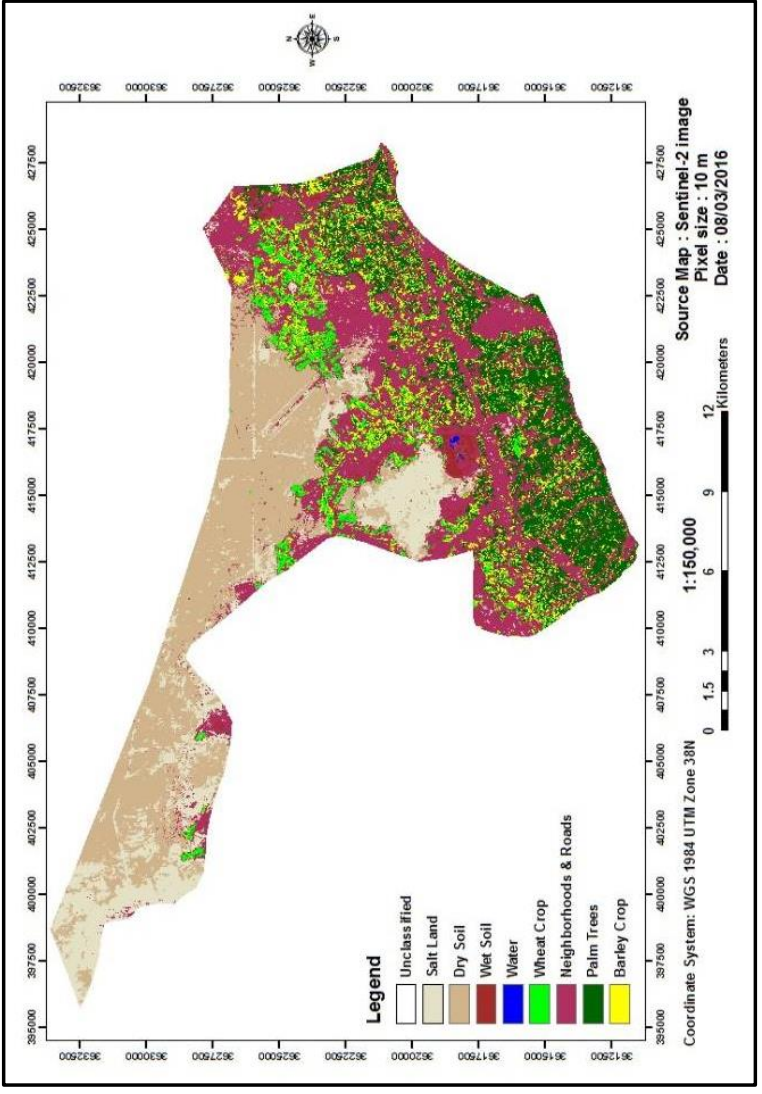

Fig. 18. Classification of the Agriculture Division of Imam Aoun by maximum likelihood method for Sentinel-2 image on 08-03-2016.

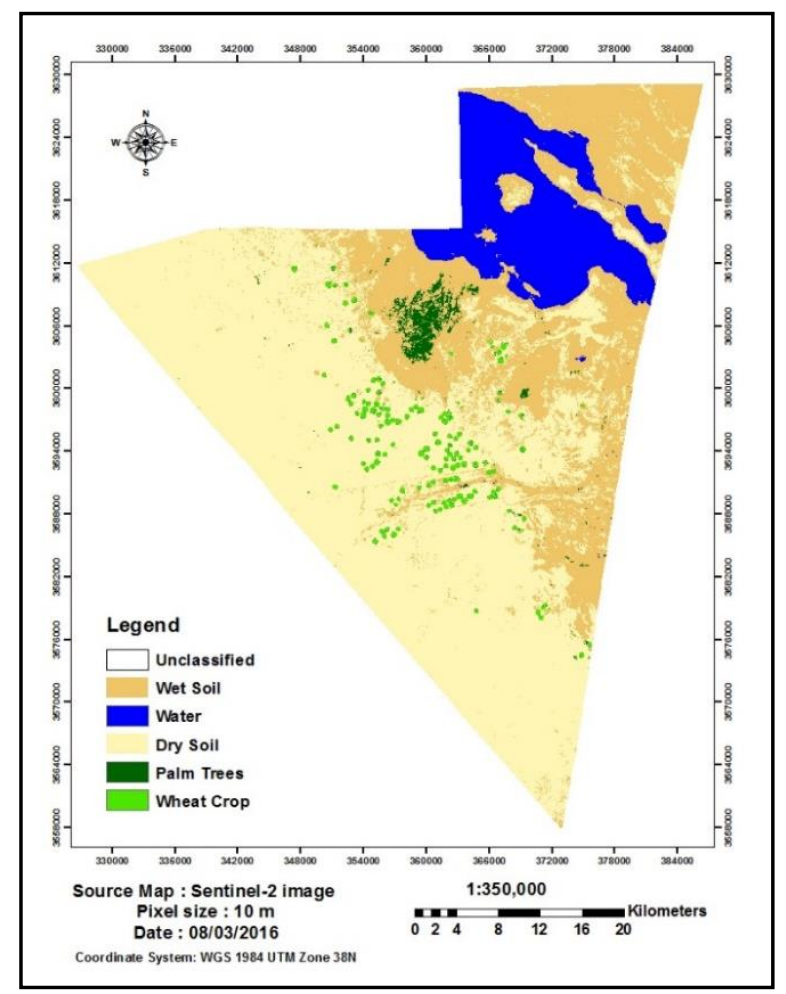

Fig. 19. Classification by Maximum likelihood method to Ain al-Tamur Agriculture Division for Sentinel-2 image on 08-032016.
Table 7. Supervised classification results of Ain al-Tamur Agriculture Division

\begin{tabular}{|c|c|c|}
\hline \multirow{2}{*}{ Data } & Difference & $\begin{array}{c}\text { Maximum } \\
\text { likelihood }\end{array}$ \\
\hline \multirow{2}{*}{$\begin{array}{c}\text { Sentinel-2 image } \\
\text { on 08-03-2016 }\end{array}$} & $\begin{array}{c}\text { Overall } \\
\text { classification } \\
\text { accuracy }\end{array}$ & $97.50 \%$ \\
\cline { 2 - 3 } & $\begin{array}{c}\text { Overall statistics } \\
\text { kappa }\end{array}$ & 0.9688 \\
\cline { 2 - 3 } & Area of wheat crop & 10739 Donum \\
\hline
\end{tabular}

\section{Conclusions}

1. The effectiveness of spatial-resolution 10 meters in agricultural applications.

2. Efficiency indicators used to determine the damage to the phenomenon in the crop in record time too.

3. Production pivotal farms spray twice more than farms that depend surface irrigation.

4. Agricultural Meteorological data contributed to the finding and interpretation of the increase or the decline in farms during monitoring period.

5. Ain al-Tamur farms are considered an important source of wheat due to the clean water quality and the quality of virgin territory and irrigation sprinkler.

\section{References}

1. Isabel Patricia Maria Coppa, "The Use of Remote Sensing data For Broad Acre Grain crop Monitoring in Southeast Australia", PhD Thesis, SET Portfolio, RMIT University, Geospatial Science, School of Mathematical and Geospatial Sciences, Melbourne, Australia (2006).

2. Ghilani C. Wolf P, "Elementary Surveying an Introduction to Geomatics",(13th edition, U.S., The Pennsylvania State University \& Environmental Engineering University of Wisconsin-Madison 2012).

3. European Space Agency site 2016.

http://www.esa.int/Our_Activities/Observing the Ea rth/Copernicus/Sentinel-2

4. Wise K. Johnson B. Mansfield C. Krupke C, "Managing Wheat by Growth Stage" (University PURDUE2013).

5. Kent McVay, Mary Burrows, Fabian Menalled and Kevin Wanner "Montana Wheat Production Guide" (Publication, Montana state University 2010).

6. Saeed M. Jassem M. Kadhim F, "Thermal Limits and Their Effect on Wheat and Barley Crops at Baladruz District" Diyala Magazine, 66, 411-426, (in Arabic) (2015).

7. Basso B. Cammarano D. Carfagna E, "Review of Crop Yield Forecasting Methods and Early Warning Systems" Research Report, Michigan 